\title{
Investigation of the Linkage among China's Macroeconomy, Stock Market and Real Estate Market
}

\author{
GUO Jianhua ${ }^{\mathrm{a}}$, LONG Huidian ${ }^{\mathrm{b}}$ \\ ${ }^{a}$ School of Mathematics and Computing Science; Hunan University of Science and Technology; Xiangtan 411201; P.R.China \\ ${ }^{b}$ School of Information; Guangdong Foreign Studies University; Guangzhou 510420; P.R.China
}

\begin{abstract}
As two important constituents of China's macro economy, there are a variety of relationships among China's stock market, real estate market and its macro economy. In order to investigate these relationships, in this paper, especially with the Macroeconomic Boom Index reflecting China's macro economy, we use cointegration theory and Granger analysis to demonstrate that there are long-term equilibrium relationship and bidirectional causality between the macro economy and the securities business, also between the macro economy and the real estate market, however, this kind of long-term Equilibrium relationship and bidirectional causality appears very weak.
\end{abstract}

Keywords: Macroeconomy; Stock Market; Real Estate Market; Linkage; Cointegration; Granger Causality Test

\section{(C) 2013 Published by SSBFNET}

\section{Introduction}

Many scholars have researched the correlationship among macroeconomy, security market and real estate market. Among them, Bharat and $\operatorname{Zan}(2002)$ studied the relationship between the real estate prices and national incomes in Sweden and U.K. and their results showed that Swedish national income induced real estate price's fluctuation while there was causality between British national income and housing price. Tsatsaronis and Zhu(2004), by constructing VAR model comprising actual housing price, CPI, GDP and short-term interest rate, decided that the real estate price was mostly effected by inflation while weakly effected by national income. Iacoviello and Minetti(2006) researched the influence of real estate on macroeconomic fluctution and concluded that the change of real estate price significantly activated national consumption. Demary(2009) studied ten OCED countries' correlation among their housing price, inflation rate and interest rate, and found that the macroeconomy heavily effected the real estate price. George et al(2005) constructed VAR model and VEC model and studied the relationship between Germanic stock market and macroeconomy, the research result demonstrated that the flourishing stock market could accelerate the development of macroeconomy. Nieuwerburgh et al(2006) analyzed the relationship between Belgium's stock market and macroeconomy and realized that the stock market might discriminatively boost economic growth at different stage, i.e., there are different relationships between stock market and macroeconomy under different circumstances. Muhammad S. et al(2008) studied how Pakistan's stock market influenced its macroeconomic development at longterm and at short-term, respectively, they acquired results as there existed mutual causality between stock market and macroeconomy in the long run while only unidirectional influence from the former to the latter in the short run. Similarly, Enisan et al(2009) tested the causality between African stock markets and macroeconomy based on VEC 
model and cointegration test.

In this paper, by using of Granger causality test method and relying on VAR and VEC model while with macroeconomic climate index reflecting China's macroeconomy situation, we study the correlation among China's macroeconomy, stock market and real estate market. Our research includes whether there is long-term equilibrium relationship or short-term correlation among aforementioned three markets; whether and how the fluctuation of macroeconomy cause real estate's and stock market's change; whether and how real estate's and stock market's fluctuation affect macroeconomic situation. Our findings indicate that there are long-term equilibrium relationship and bidirectional causality between the macroeconomy and the securities business, also between the macroeconomy and the real estate market, however, this kind of extended Equilibrium relationship and bidirectional causality appears very weak.

The rest of paper is organized as follows. In section 2, the basic variables and model are introduced. Section 3 considers how to select sample data, in section 4, empirical analysis is conducted to demonstrate the relationship among china's macroeconomy, stock market and real estate market, while the last section concludes.

\section{Variable and Model}

\subsection{Selection of variable}

When select variable, we usually take its economic signification into account besides the possibility to collect corresponding data. In this paper, we mostly study the linkage among china's macroeconomy, stock market and real estate market, thus, we select macroeconomic climate index to reflect situation of China's macroeconomy, while choosing Shanghai Composite Index and Real Estate Climate Index scaling China's stock market real estate market, respectively.

\subsection{Basic model}

As to multidimensional time serial $y_{t}=\left(y_{1 t}, \cdots, y_{k t}\right)$

$$
\text { Call } y_{t} \sim C I(d, b) \text {, if } y_{i t} \sim I(d), i=1, \cdots, k \text { and } \beta^{\prime} y_{t} \sim I(d-b) \text { with nonzero vector } \beta \text {. }
$$

Call expression (1) as a VAR(p) model,

$$
y_{t}=A_{1} y_{t-1}+\cdots A_{p} y_{t-p}+U_{t}
$$

Where $y_{i t}, i=1, \cdots, k$ denote nonstationary $I(1)$ variables; $A_{j}, j=1, \cdots, p$, k-rank parameter matrix; and

$U_{t}$, k-dimension error vector.

When denote $\Pi=\sum_{i=1}^{p} A_{i}-I$, which is called compressed matrix, and $\Gamma_{i}=-\sum_{j=i+1}^{p} A_{j}(i=1, \cdots, p-1)$, we can make difference to (1) and get

$$
\Delta y_{t}=\Pi y_{t-1}+\sum_{i=1}^{p-1} \Gamma_{i} \Delta y_{t-i}+U_{t}
$$


As a result of assuming $y_{t} \sim I(1)$, thus, $\Delta y_{t} \sim I(0)$. In (2),all terms, with except of $\Pi y_{t-1}$, are stationary. So,there is not cointegration among all components of $y_{t}$ when $\Pi y_{t-1}$ being nonstationary,and vice versa. Suppose $\operatorname{rank}(\Pi)=r$, which indicates there being $r$ cointegrations, then, $\Pi$ can be decomposed into $\Pi=\alpha \beta^{\prime}$, where $\alpha, \beta$ are $k \times r$ rank matrice and $\operatorname{rank}(\alpha)=\operatorname{rank}(\beta)=r$. Let $\operatorname{vecm}_{t-1}:=\beta^{\prime} y_{t-1}$ as error correct term,there is

$$
\Delta y_{t}=\alpha v e c m_{t-1}+\sum_{i=1}^{p-1} \Gamma_{i} \Delta y_{t-i}+U_{t}
$$

(3) is called a error correct model of a cointegration system. vecm ${ }_{t-1}:=\beta^{\prime} y_{t-1}$ reflects equilibria relationship of system in the long run.

\section{Data}

Take acquirability and synchronization into account, In this paper, we select monthly historic data of national real estate climate index from January,1999 through September,2012 to refletc real estate market while selecting homochronous Shanghai Securities Complex Index and macroeconomic climate index to reflect china's stock market and macroeconomic situation, respectively. In order to eliminate influence of seasonal factor and heteroskedasticity, we first adjust all original data with X12 method and make logarithmic operation, signing as $\ln (\mathrm{RECI}), \ln (\mathrm{SHCI})$ and $\ln (\mathrm{MECI})$. Seeing figure 1.

Seeing from figure 1, we can know that china's macroeconomy, stock market and real estate market run equilibriumly in the long run, however, there are deviation instances in the short run.
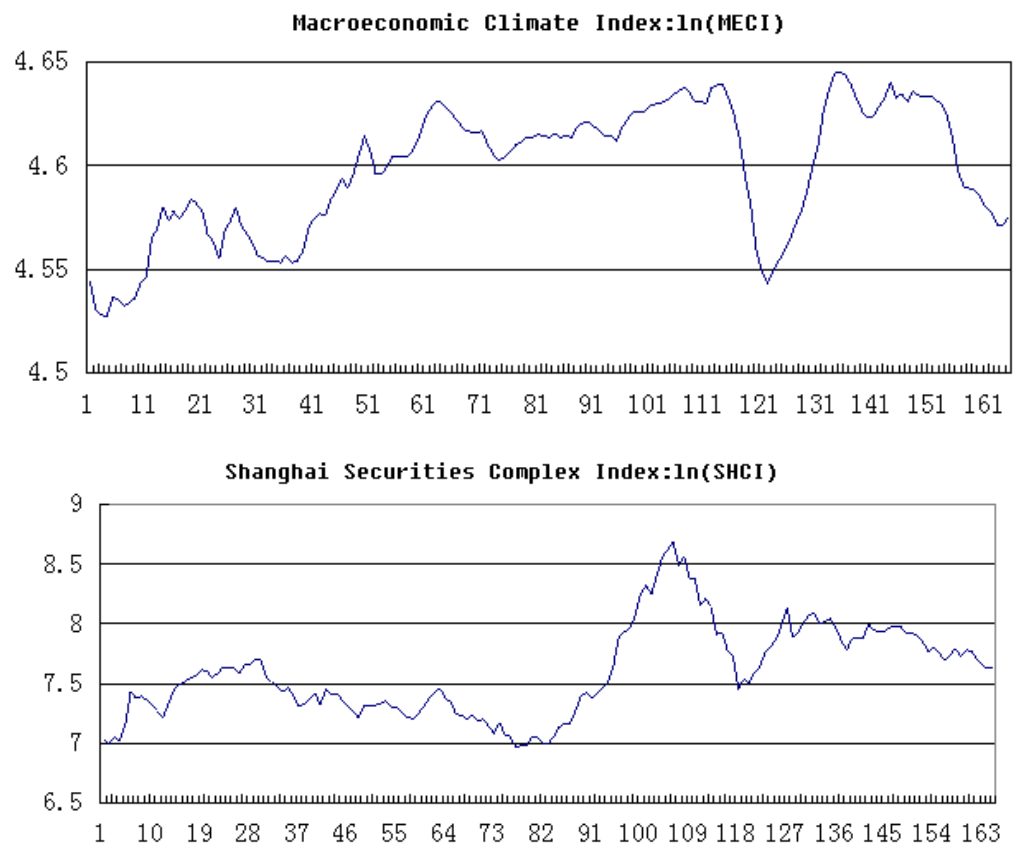


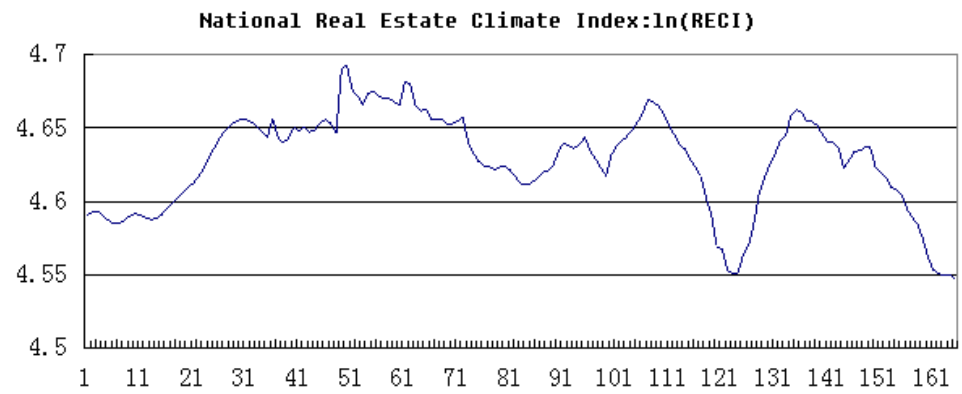

Fig 1 Trend of Macroeconomic Climate Index, Shanghai Securities Complex Index and National Real Estate Climate Index

\section{Empirical Specification}

\subsection{Stationarity testing}

In order to avoid fallacious regression, empirical analysis demands time series being stationary, and ADF testing is a conventional method to test stationarity of time series. From figure 1, it's difficulty to decide whether three time series are of marked trend, here, we verify the stationarity with following models in turn.

If there seems existing constant term and trend term in time series, the testing model can be

$$
\Delta y_{t}=\alpha+\beta t+\delta y_{t-1}+\sum_{j=1}^{p} \lambda_{j} \Delta y_{t-j}+u_{t}
$$

If there seems being no trend term but being nonzero mean value, the testing model will be

$$
\Delta y_{t}=\alpha+\delta y_{t-1}+\sum_{j=1}^{p} \lambda_{j} \Delta y_{t-j}+u_{t}
$$

Else if there seems being no trend term and no constant term and the time series is fluctuating around zero,the testing moedel can be

$$
\Delta y_{t}=\delta y_{t-1}+\sum_{j=1}^{p} \lambda_{j} \Delta y_{t-j}+u_{t}
$$

In ADF testing, the number of laging terms may be ascertained by AIC criterion or SIC criterion, here, we select number of laging terms to be 2 and do unit root test with software Eviews. The testing results are showed in table 1 as following.

As seen in table 1, three logarithmic time series are not stationary but the differenced time series of them are stationary, i.e., $\ln (\mathrm{MECI}), \ln (\mathrm{SHCI})$ and $\ln (\mathrm{RECI})$ are I(1) time series, we can do cointegration testing for them. 
Table 1 Unit Root Testing

\begin{tabular}{|c|c|c|c|c|}
\hline & \multicolumn{3}{|c|}{ ADF value } & \multirow{2}{*}{ Stationarity } \\
\hline & Model(4) & Model(5) & Model(6) & \\
\hline $\operatorname{Ln}(\mathrm{MECI})$ & -3.102152 & -3.467285 & 0.386566 & $\mathrm{NO}$ \\
\hline $\mathrm{Ln}(\mathrm{SHCI})$ & -1.562866 & -1.769621 & -0.105709 & $\mathrm{NO}$ \\
\hline Ln(RECI) & -1.745272 & -1.468392 & -0.362758 & $\mathrm{NO}$ \\
\hline dLn(MECI) & $-10.08320 * * *$ & $-9.921276^{* * *}$ & $-9.933355 * * *$ & YES \\
\hline $\mathrm{dLn}(\mathrm{SHCI})$ & $-7.139804 * * *$ & $-7.108832 * * *$ & $-7.113474 * * *$ & YES \\
\hline $\mathrm{dLn}(\mathrm{RECI})$ & $-9.099092 * * *$ & $-8.937749 * * *$ & $-8.955171 * * *$ & YES \\
\hline
\end{tabular}

\subsection{Cointegration Testing}

Now, we respectively use Johansen testing method and EG testing method to test the cointegration relationship among $\ln (\mathrm{MECI}), \ln (\mathrm{SHCI})$ and $\ln (\mathrm{RECI})$. The results are just as in table 2 and table 3. firstly, the testing results of two kinds of method are consistent, then, we can decide that there exists cointegration relationship between $\ln (\mathrm{MECI})$ and $\ln (\mathrm{RECI})$ and between $\ln (\mathrm{MECI})$ and $\ln (\mathrm{SHCI})$, but there does not exist cointegration relationship between $\ln (\mathrm{SHCI})$ and $\ln (\mathrm{RECI})$. By this token, in China, the macroeconomy is keep long-term equilibrium relationship with stock market and so does between macroeconomy and real estate market, which is in accord with other scholars' results, however, there is not obvious equilibrium relationship between China's stock market and real estate market.

Table 2 Johansen Cointegration Testing

\begin{tabular}{|c|c|c|c|}
\hline & $\begin{array}{l}\text { Hypothesized } \\
\text { No. of } \mathrm{CE}(\mathrm{s})\end{array}$ & Trace Statistic & Max-Eigen Statistic \\
\hline $\operatorname{Ln}(\mathrm{MECI})$ & None * & $19.04725(15.49471)[0.0139]$ & $15.21074(14.26460)[0.0353]$ \\
\hline$\& \ln (\mathrm{SHCI})$ & At most 1 & $3.836511(3.841466)[0.0501]$ & $3.836511(3.841466)[0.0501]$ \\
\hline Ln(MECI) & None * & $18.53170(15.49471)[0.0169]$ & $14.83535(14.26460)[0.0406]$ \\
\hline$\& \ln (\mathrm{RECI})$ & At most 1 & $3.696352(3.841466)[0.0545]$ & $3.696352(3.841466)[0.0545]$ \\
\hline $\operatorname{Ln}(\mathrm{RECI})$ & None & $13.03136(15.49471)[0.1137]$ & $11.97331(14.26460)[0.1117]$ \\
\hline$\& \ln (\mathrm{SHCI})$ & At most 1 & $1.058052(3.841466)[0.3037]$ & $1.058052(3.841466)[0.3037]$ \\
\hline
\end{tabular}

Tabel 3 EG Cointegration Testing

\begin{tabular}{|l|c|c|c|}
\hline & ADF of residual error time series & t-statistic & Stationarity of residual error time series \\
\hline $\ln (\mathrm{MECI}) \& \ln (\mathrm{SHCI})$ & -2.05192 & -1.94287 & YES \\
\hline $\ln (\mathrm{MECI}) \& \ln (\mathrm{RECI})$ & -2.22173 & -1.94278 & YES \\
\hline $\ln (\mathrm{SHCI}) \& \ln (\mathrm{RECI})$ & -1.72279 & -1.94278 & NO \\
\hline
\end{tabular}

\subsection{Granger Causality Testing}

By Grange expression theorem, if there exists cointegration between variables, there is at least one grange causality from one variable to the other. So, according to the preceding results, it is necessary for us to judge the causality among $\ln (\mathrm{MECI}), \ln (\mathrm{RECI})$ and $\operatorname{lnSHCI}$.

However, the Grange Causality Testing is aim at stationary time series, so, we first make difference operation to time series $\ln (\mathrm{MECI}) \ln (\mathrm{RECI})$ and $\ln \mathrm{SHCI}$, respectively. The results of grange causality testing are showed in table 4, from which, we can see that it is real that there is bidirectional granger causality between China's macroeconomy and stoch market under significant level 5\%, and so does between China's macroeconomy and real estate market, which is true to economicial common sense. 
Table 4 Granger Causality Testing

$\begin{array}{ccccc}\text { Null Hypothesis: } & \text { Obs } & \text { F-Statistic } & \text { Prob. } & \text { conclusion } \\ \text { D(LNRECI) does not Granger Cause D(LNMECI) } & 161 & 3.74737 & 0.0124 & \text { Reject } \\ \text { D(LNMECI) does not Granger Cause D(LNRECI) } & & 3.08733 & 0.0290 & \text { Reject } \\ \text { D(LNSHCI) does not Granger Cause D(LNMECI) } & 161 & 3.34890 & 0.0117 & \text { Reject } \\ \text { D(LNMECI) does not Granger Cause D(LNSHCI) } & & 2.88897 & 0.0243 & \text { Reject } \\ \text { D(LNSHCI) does not Granger Cause D(LNRECI) } & 161 & 3.19267 & 0.0253 & \text { Reject } \\ \text { D(LNRECI) does not Granger Cause D(LNSHCI) } & & 1.68350 & 0.1729 & \text { No rejecting }\end{array}$

Note:according to AIC criterion, here, the number of lagging terms is 3.

\section{Conclusion and Further Research}

In this paper, we have investigated the correlationship among China's macroeconomy, stock market and real estate market and conclusions as following can be concluded

Generally speaking, China's macroeconomy keeps long-term equilibrium and bidirectional causality with the stock market, however, because of the juvenility of China's securities market, both of China's macroeconomy and stock market only weakly influence each other, this kind of feeble interaction demonstrates that China's securities market, as a component of China's macroeconomy, does not exhibit its proper function to the latter. So, as a conclusion, China ought to enlarge its stock market's scale, transform its government functions that intervene too much to stock market's development, and in China, investors should more reasoningly invest instead of taking a risk.

Similarly, we also find there exists a long-term equilibrium relationship and bidirectional causality between China's macroeconomy and real estate market. In fact, on the one hand, development of China's real estate market has become an important constitute of its macroeconomy, however, on the other hand, for Chinese government, it shall be alert to excessively rely on real estate to accelerate macroeconomic development, or else real estate bubble may come into being. Hence, Chinese government should properly regulate the real estate market and control it in its correct development orbit.

However, our research indicates that no obvious long-term equibrium or causality exists between China's stock market and real estate market, which tells us that, in China, these two financial markets can not effectively substitute each other, In addition, adjustment of china's dummy economy will not arouse change in substantiality economy. So, we must synchronously boost two markets, only in this way, China's macroeconomy can truely boom.

Lastly, in this paper, we only investigated the correlationship among China's macroeconomy, stock market and real eatate market, and we did not construct quantitative model to scale this kind of correlationship, which is our further study in this domain.

\section{References}

Bharat, Barot, and Yang Zan. (2002).Housing Prices and Housing Investment in Sweden and the United K ingdom. Econometric Analysis for the Period 1970-1998. 0Review of Urban and Regional Development Studies, 2,189-216.

Tsatsaronis, K and H Zhu .(2004). What drives housing price dynamics: Cross-country evidence, BIS Quarterly Review, March:65-78. 
Iacoviello, Matteo,and Raoul Minetti.(2006). The Credit Channel of Monetary Policy: Evidence from the Housing Market.Journal of Macroeconomics,30:1,69-96. http://dx.doi.org/10.1016/j.jmacro.2006.12.001

Demary, Markus. (2009). The Link between Output,Inflation, Monetary Policy and Housing Price Dynamics.University Library of Munich MPRA paper,No.15978.

George Hondroyiannis,Sarantis Lolos,Evangelia Papapetrou. (2005).Financial markets and economic growth in Greece, 1986-1999. Int. Fin. Markets, Inst. and Money, 15,173-188. http://dx.doi.org/10.1016/j.intfin.2004.03.006

Stijn Van Nieuwerburgh, Frans Buelens, Ludo Cuyvers. (2006).Stock market development and economic growth in Belgium. Explorations in Economic History,43,13--38. http://dx.doi.org/10.1016/j.eeh.2005.06.002

Muhammad Shahbaz, Nadeem Ahmed, Liaquat Ali. (2008).Stock Market Development and Economic Growth: Ardl Causality in Pakistan. International Research Journal of Finance and Economics, 14,182-195

Akinlo A. Enisan, Akinlo O.Olufisayo.(2009).Stock market development and economic growth: Evidence from seven sub-Sahara African countries.Journal of Economics and Business, 61:2,162-171. http://dx.doi.org/10.1016/j.jeconbus.2008.05.001 